\title{
HUBUNGAN RUANG NULL DAN RUANG PETA PADA MATRIKS IDEMPOTEN
}

\author{
RATIH ANJELI PUTRI, YANITA*, MONIKA RIANTI HELMI \\ Program Studi S1 Matematika, \\ Fakultas Matematika dan Ilmu Pengetahuan Alam, Universitas Andalas, \\ Kampus UNAND Limau Manis Padang, Indonesia. \\ email : ratihanjelina131214@gmail.com, yanita@sci.unand.ac.id, \\ monikariantihelmi@sci.unand.ac.id
}

Diterima 15 Desember 2020 Direvisi 29 Desember 2020 Dipublikasikan 12 Januari 2021

\begin{abstract}
Abstrak. Ruang null dari matriks $A$ yang berukuran $m \times n$ adalah himpunan semua solusi untuk persamaan $A \mathbf{x}=\mathbf{0}$ dan ruang peta dari matriks $A$ yang berukuran $m \times n$ adalah himpunan semua solusi untuk persamaan $A \mathbf{x}=\mathbf{y}$. Misalkan matriks $A$ berukuran $n \times n$ dikatakan matriks idempoten jika $A^{2}=A$. Matriks $A$ dan $B$ adalah Dua matriks idempoten dikatakan komutatif nol jika $A B=B A=\mathbb{O}$. Tulisan ini mengkaji hubungan ruang null dan ruang peta pada matriks idempoten.
\end{abstract}

Kata Kunci: Ruang Null, Ruang Peta, Matriks Idempoten.

\section{Pendahuluan}

Konsep matriks menjadi salah satu pembahasan penting dalam bidang aljabar linier. Kajian terhadap matriks menjadi lebih luas dan diperumun. Matriks memudahkan untuk membuat analisa-analisa yang mencakup hubungan variabel-variabel dari suatu persoalan. Ruang null dari matriks $A$ yang berukuran $m \times n$ adalah himpunan semua solusi untuk persamaan $A \mathbf{x}=\mathbf{0}$ dapat dinyatakan dengan $N(A)=\left\{\mathbf{x} \in \mathbb{R}^{n \times 1} \mid A \mathbf{x}=\mathbf{0}\right\}$ dan ruang peta dari matriks $A$ yang berukuran $m \times n$ adalah himpunan semua solusi untuk persamaan $A \mathbf{x}=\mathbf{y}$ dapat dinyatakan dengan $R(A)=\left\{\mathbf{y} \in \mathbb{R}^{m \times 1} \mid A \mathbf{x}=\mathbf{y}\right\}$.

Pada teori matriks terdapat berbagai jenis matriks, salah satunya matriks idempoten. Matriks idempoten A adalah matriks bujursangkar yang apabila dikalikan dengan dirinya sendiri merupakan matriks itu sendiri atau $A^{2}=A$. Tulisan ini mengkaji hubungan ruang null dan ruang peta pada matriks idempoten.

*penulis korespondensi 


\section{Landasan Teori}

\subsection{Matriks Idempoten}

Definisi 2.1. [3] Misalkan matriks $A$ berukuran $n \times n$ dikatakan matriks idempoten jika $A^{2}=A$ atau $A^{n}=A$ untuk suatu $n \geqslant 2$.

Lema 2.2. [3] Misalkan $\left(I_{n}-A\right)$ adalah matriks idempoten jika dan hanya jika matriks $A$ adalah matriks idempoten.

Definisi 2.3. [5] Matriks $A$ dan matriks $B$ adalah dua matriks idempoten yang komutatif jika $A B=B A$ dan dikatakan komutatif nol jika $A B=B A=\mathbb{O}$.

\subsection{Ruang Null dan Ruang Peta Suatu Matriks}

Teorema 2.4. [1] Misalkan $W$ adalah himpunan bagian tak kosong dari ruang vektor $V$. Himpunan $W$ adalah subruang dari $V$ jika dan hanya jika syarat-syarat berikut terpenuhi.

(a) Jika $\mathbf{u}$ dan $\mathbf{z}$ adalah vektor-vektor pada $W$ maka $\mathbf{u}+\mathbf{z}$ berada pada $W$.

(b) Jika $k$ adalah skalar sebarang dan $\mathbf{u}$ adalah vektor sebarang pada $W$ maka $k \mathbf{u}$ berada pada $W$.

Definisi 2.5. [4] Misalkan $U$ dan $W$ adalah subruang dari ruang vektor $V$. Ruang vektor $V=U \oplus W$ jika

(a) $U \cap W=\{\mathbf{0}\}$,

(b) $V=U+W$

Dalam hal ini $V$ dikatakan sebagai jumlah langsung dari $U$ dan $W$.

Definisi 2.6. [2] Misalkan $A$ adalah matriks berukuran $m \times n, \mathbf{x}$ adalah matriks berukuran $n \times 1$, dan $\mathbf{0}$ adalah matriks berukuran $m \times 1$ maka ruang null dari matriks $A$ adalah himpunan semua solusi untuk persamaan $A \mathbf{x}=\mathbf{0}$ dapat dinyatakan den$\operatorname{gan} N(A)=\left\{\mathbf{x} \in \mathbb{R}^{n \times 1} \mid A \mathbf{x}=\mathbf{0}\right\}$.

Definisi 2.7. [2] Misalkan $A$ adalah matriks berukuran $m \times n, \mathbf{x}$ adalah matriks berukuran $n \times 1$, dan $\mathbf{y}$ adalah matriks berukuran $m \times 1$ maka ruang peta dari matriks $A$ adalah himpunan semua solusi untuk persamaan $A \mathbf{x}=\mathbf{y}$ dapat dinyatakan den$\operatorname{gan} R(A)=\left\{\mathbf{y} \in \mathbb{R}^{m \times 1} \mid A \mathbf{x}=\mathbf{y}\right\}$.

\section{Pembahasan}

\subsection{Hubungan Ruang Null dan Ruang Peta pada Matriks Idempoten}

Lema 3.1. [2] Misalkan A adalah matriks idempoten maka ruang peta dari matriks idempoten $A$ adalah $R(A)=\left\{\mathbf{y} \in \mathbb{R}^{n \times 1} \mid A \mathbf{y}=\mathbf{y}\right\}$ jika dan hanya jika $\mathbf{y} \in R(A)$.

Lema 3.2. [3] Misalkan $N(A)=R(I-A)$ jika dan hanya jika matriks $A$ adalah matriks idempoten. 
Proposisi 3.3. [5] Misalkan $A$ dan $B$ adalah matriks idempoten $A=A B$ dan $B=B A$ jika dan hanya jika $N(A)=N(B)$.

Bukti. Untuk sebarang $\mathbf{x} \in N(A)$ maka $A \mathbf{x}=\mathbf{0}$, jadi $B A \mathbf{x}=\mathbf{0}$. Oleh karena $B A=B$ maka $B \mathbf{x}=\mathbf{0}$ akibatnya $\mathbf{x} \in N(B)$. Oleh karena itu $N(A) \subseteq N(B)$. Demikian juga $N(B) \subseteq N(A)$. Sehingga diperoleh $N(A)=N(B)$. Untuk sebarang $\mathbf{y} \in N(A)$ maka

$$
\begin{aligned}
N(A) & =\left\{\mathbf{y} \in \mathbb{R}^{n \times 1} \mid A \mathbf{y}=\mathbf{0}\right\} \\
& =\left\{\mathbf{y} \in \mathbb{R}^{n \times 1} \mid(I-A) \mathbf{y}=\mathbf{y}\right\} .
\end{aligned}
$$

Dari persamaan (3.1) dan (3.2) diperoleh $A(I-A) \mathbf{y}=\mathbf{0}$ akibatnya $(I-A) \mathbf{y} \in$ $N(A)$. Oleh karena $N(A)=N(B)$ maka $(I-A) \mathbf{y} \in N(B)$ sehingga diperoleh $B(I-A) \mathbf{y}=\mathbf{0}$ akibatnya $B(I-A)=\mathbb{O}$ atau $B=B A$. Demikian juga $A B=A$.

Proposisi 3.4. [5] Jika $A$ dan $B$ adalah matriks idempoten yang komutatif dan $R(A) \cap R(B)=\{\mathbf{0}\}$ maka $N(A-B)=N(A) \cap N(B)$.

Bukti. Misalkan untuk sebarang $\mathbf{x} \in N(A-B)$ maka $(A-B) \mathbf{x}=\mathbf{0}$ jika dan hanya jika $A \mathbf{x}=B \mathbf{x}$. Perhatikan bahwa $A \mathbf{x}=A^{2} \mathbf{x}=A B \mathbf{x}=B A \mathbf{x}$ maka diperoleh $(I-B) A \mathbf{x}=\mathbf{0}$. Akibatnya $A \mathbf{x} \in N(I-B)=R(B)$. Oleh karena $A \mathbf{x}, B \mathbf{x} \in R(B)$. Demikian juga dari $B \mathbf{x}=A B \mathbf{x}$ diperoleh $A \mathbf{x}, B \mathbf{x} \in R(A)$. Jadi $A \mathbf{x}, B \mathbf{x} \in R(A) \cap$ $R(B)=\{\mathbf{0}\}$ maka $A \mathbf{x}=\mathbf{0}$ dan $B \mathbf{x}=\mathbf{0}$ akibatnya $\mathbf{x} \in N(A)$ dan $\mathbf{x} \in N(B)$. Jadi $\mathbf{x} \in N(A) \cap N(B)$ sehingga $N(A-B) \subseteq N(A) \cap N(B)$

Selanjutnya untuk sebarang $\mathbf{y} \in N(A) \cap N(B)$ maka $A \mathbf{y}=\mathbf{0}$ dan $B \mathbf{y}=\mathbf{0}$ sehingga diperoleh $A \mathbf{y}=B \mathbf{y}$ dengan kata lain $(A-B) \mathbf{y}=\mathbf{0}$. Jadi $\mathbf{y} \in N(A-B)$ akibatnya $N(A) \cap N(B) \subseteq N(A-B)$ sehingga diperoleh $N(A-B)=N(A) \cap N(B$.

Proposisi 3.5. [5] Jika $A$ dan $B$ adalah matriks idempoten yang komutatif dan $\mathbf{y} \in R(B)$ maka $R(B(I-A))=N(A)$.

Bukti. Untuk sebarang $\mathbf{x} \in R(B(I-A))$ maka $B(I-A) \mathbf{x}=\mathbf{x}=\mathbf{0}$. Oleh karena itu $\mathbf{x} \in N(A)$ akibatnya $R(B(I-A)) \subseteq N(A)$. Selanjutnya untuk sebarang $\mathbf{y} \in N(A)$ maka $A \mathbf{y}=\mathbf{0}$ dan $B A \mathbf{y}=\mathbf{0}$ maka $B A \mathbf{y}-B \mathbf{y}=-B \mathbf{y}$. Oleh karena $\mathbf{y}=B \mathbf{y}$ akibatnya $B(I-A) \mathbf{y}=\mathbf{y}$. Jadi $\mathbf{y} \in R(B(I-A))$ akibatnya $N(A) \subseteq R(B(I-A))$ sehingga $R(B(I-A))=N(A)$.

Proposisi 3.6. [5] Jika $A$ dan $B$ adalah matriks idempoten yang komutatif nol $\operatorname{maka} R(A+B)=R(A)+R(B)$.

Bukti. Misalkan untuk sebarang $\mathbf{x}=\mathbf{x}_{\mathbf{1}}+\mathbf{x}_{\mathbf{2}} \in R(A)+R(B)$. Dimana $\mathbf{x}_{\mathbf{1}} \in R(A)$ dan $\mathbf{x}_{\mathbf{2}} \in R(B)$ maka $\mathbf{x}_{\mathbf{1}}=A \mathbf{x}_{\mathbf{1}}$ dan $\mathbf{x}_{\mathbf{2}}=B \mathbf{x}_{\mathbf{2}}$. Perhatikan bahwa

$$
\begin{aligned}
(A+B)\left(\mathbf{x}_{\mathbf{1}}+\mathbf{x}_{\mathbf{2}}\right) & =A \mathbf{x}_{\mathbf{1}}+A \mathbf{x}_{\mathbf{2}}+B \mathbf{x}_{\mathbf{1}}+B \mathbf{x}_{\mathbf{2}} \\
& =\mathbf{x}_{\mathbf{1}}+\mathbf{x}_{\mathbf{2}}+B\left(\mathbf{x}_{\mathbf{1}}-\mathbf{x}_{\mathbf{1}}\right)+A\left(\mathbf{x}_{\mathbf{2}}-\mathbf{x}_{\mathbf{2}}\right) \\
& =\mathbf{x}_{\mathbf{1}}+\mathbf{x}_{\mathbf{2}}=\mathbf{x} .
\end{aligned}
$$


Oleh karena $\mathbf{x}=\mathbf{x}_{\mathbf{1}}+\mathbf{x}_{\mathbf{2}} \in R(A+B)$ akibatnya $R(A)+R(B) \subseteq R(A+B)$.

Selanjutnya untuk sebarang $\mathbf{y} \in R(A+B)$ maka $\mathbf{y}=(A+B) \mathbf{y}=A \mathbf{y}+B \mathbf{y}$. Misalkan $\mathbf{y}_{\mathbf{1}}=A \mathbf{y}$ dan kedua ruas sama-sama dikalikan dengan $A$ maka $A \mathbf{y}_{\mathbf{1}}=$ $A A \mathbf{y}=\mathbf{y}_{\mathbf{1}}$. Akibatnya $\mathbf{y}_{\mathbf{1}} \in R(A)$. Misalkan $\mathbf{y}_{\mathbf{2}}=B \mathbf{y}$ dan kedua ruas sama-sama dikalikan dengan $B$ maka $B \mathbf{y}_{2}=B B \mathbf{y}=\mathbf{y}_{\mathbf{2}}$. Akibatnya $\mathbf{y}_{\mathbf{2}} \in R(B)$. Oleh karena $\mathbf{y}=\mathbf{y}_{\mathbf{1}}+\mathbf{y}_{\mathbf{2}} \in R(A)+R(B)$ sehingga diperoleh $R(A+B) \subseteq R(A)+R(B)$. Jadi $R(A+B)=R(A)+R(B)$.

Akibat 3.7. [3] Jika $A$ adalah matriks idempoten yang komutatif nol maka $\mathbb{R}^{n}=$ $R(A)+N(A)$.

Bukti. Berdasarkan persamaan (3.1) dan (3.2) diperoleh $A(I-A)=(I-A) A=$ O. Akibatnya $A$ dan $(I-A)$ merupakan matriks idempoten yang komutatif nol. Selanjutnya berdasarkan Proposisi 3.6 diperoleh $R(A+I-A)=R(A)+R(I-A)$ akibatnya $R(I)=R(A)+N(A)$. Oleh karena itu $\mathbb{R}^{n}=R(A)+N(A)$.

Proposisi 3.8. [5] Jika $A$ adalah matriks idempoten maka $\mathbb{R}^{n}=R(A) \oplus N(A)$.

Bukti. Untuk sebarang $\mathbf{x} \in R(A) \cap N(A)$ maka $\mathbf{x} \in R(A)$ dan $\mathbf{x} \in N(A)$. Oleh karena itu $\mathbf{x}=A \mathbf{x}$ dan $A \mathbf{x}=\mathbf{0}$. Jadi $\mathbf{x}=\mathbf{0}$. Akibatnya $R(A) \cap N(A)=\{\mathbf{0}\}$. Selanjutnya dari Akibat 3.7 diperoleh $\mathbb{R}^{n}=R(A)+N(A)$. Oleh karena itu $\mathbb{R}^{n}=$ $R(A) \oplus N(A)$.

Teorema 3.9. [5] Jika $A$ dan $B$ adalah matriks idempoten yang komutatif nol dan $(A-B)$ adalah matriks non singular maka $\mathbb{R}^{n}=R(A) \oplus R(B)$.

Bukti. Misalkan untuk sebarang $\mathbf{x} \in R(A) \cap R(B)$ maka $\mathbf{x} \in R(A)$ dan $\mathbf{x} \in R(B)$. Oleh karena $A$ dan $B$ adalah matriks idempoten, maka $\mathbf{x}=A \mathbf{x}$ dan $\mathbf{x}=B \mathbf{x}$, sehingga diperoleh $A \mathbf{x}=B \mathbf{x}$ dengan kata lain $(A-B) \mathbf{x}=\mathbf{0}$. Akibatnya $\mathbf{x} \in$ $N(A-B)$. Oleh karena $(A-B)$ adalah non singular, maka $N(A-B)=\{\mathbf{0}\}$ sehingga diperoleh $\mathbf{x}=\mathbf{0}$. Akibatnya $R(A) \cap R(B)=\{\mathbf{0}\}$. Perhatikan bahwa $(A-$ $B)(I-A-B) \mathbf{x}=\mathbf{0}$ maka $(I-A-B) \mathbf{x} \in N(A-B)=\{\mathbf{0}\}$ sehingga diperoleh $(I-A-B) \mathbf{x}=\mathbf{0}$. Akibatnya berdasarkan Proposisi $3.6 \mathbf{x}=A \mathbf{x}+B \mathbf{x} \in R(A)+R(B)$ diperoleh $\mathbb{R}^{n}=R(A)+R(B)$. Oleh karena itu $\mathbb{R}^{n}=R(A) \oplus R(B)$.

Proposisi 3.10. [5] Jika $A$ dan $B$ adalah matriks idempoten yang komutatif nol maka pernyataan berikut ekuivalen :

(1) $(A-B)$ adalah non singular,

(2) $N(A) \cap N(B)=\{\mathbf{0}\}$.

Bukti. Misalkan untuk sebarang $\mathbf{x} \in N(A) \cap N(B)$, maka $A \mathbf{x}=\mathbf{0}$ dan $B \mathbf{x}=\mathbf{0}$ dengan kata lain $(A-B) \mathbf{x}=\mathbf{0}$ sehingga $\mathbf{x} \in N(A-B)$. Oleh karena $(A-B)$ non singular maka $N(A-B)=\{\mathbf{0}\}$ akibatnya $\mathbf{x}=\mathbf{0}$. Sehingga terbukti $N(A) \cap N(B)=$ $\{\mathbf{0}\}$. Selanjutnya berdasarkan Proposisi 3.4 diperoleh $N(A) \cap N(B)=N(A-B)$. Oleh karena $N(A) \cap N(B)=\{\mathbf{0}\}$ maka $N(A-B)=\{\mathbf{0}\}$ sehingga $\mathbf{x}=\mathbf{0}$. Akibatnya $(A-B)$ adalah non singular. 


\section{Kesimpulan}

Misalkan $A$ dan $B$ adalah matriks idempoten maka diperoleh hubungan ruang null dan ruang peta pada matriks idempoten tersebut sebagai berikut:

(1) $A=A B$ dan $B=B A$ jika dan hanya jika $N(A)=N(B)$.

(2) Jika $A$ dan $B$ matriks idempoten yang komutatif dan $R(A) \cap R(B)=\{\mathbf{0}\}$ maka $N(A-B)=N(A) \cap N(B)$.

(3) Jika $A$ dan $B$ matriks idempoten yang komutatif dan y $\in R(B)$ maka berlaku $R(B(I-A))=N(A)$.

(4) Jika $A$ dan $B$ merupakan matriks idempoten yang komutatif nol maka $R(A+$ $B)=R(A)+R(B)$

(5) $\mathbb{R}^{n}=R(A)+N(A)$.

(6) Jika $A$ matriks idempoten yang komutatif nol maka berlaku $\mathbb{R}^{n}=R(A) \oplus N(A)$.

(7) Jika $A$ dan $B$ matriks idempoten yang komutatif nol dan $A-B$ adalah matriks non singular maka $\mathbb{R}^{n}=R(A) \oplus R(B)$.

(8) Jika $A$ dan $B$ merupakan matriks idempoten yang komutatif nol maka pernyataan berikut ekuivalen :

(a) $(A-B)$ adalah non singular,

(b) $N(A) \cap N(B)=\{\mathbf{0}\}$.

\section{Ucapan Terima kasih}

Terimakasih kepada Bapak Admi Nazra, Bapak Syafrizal Sy, dan Bapak Ahmad Iqbal Baqi yang telah memberikan masukan dan saran sehingga penelitian ini dapat diselesaikan dengan baik.

\section{Daftar Pustaka}

[1] Anton, H dan C. Rorres. 2004. Aljabar Linier Elementer. Edisi Kedelapan. Erlangga, Jakarta.

[2] Ben-Israel, T.N.E.Greville. 2003. Generalized Inverse Theory and Aplication. Edisi 2. Springer-Verlag, New York.

[3] Harville, D.A. 2008. Matrix Algebra from a Statistician's Perspective. Springer, New York.

[4] Meyer, C.D. 2000. Matrix Analysis and Applied Linier Algebra. SIAM.

[5] Mohammed, A.S. 2008. Some Basic Properties of Idempotent Matrices. J.Education and Science. 21:124-130.

[6] Schott, James. 1996. Matrix Analysis for Statistics. A Wiley-Interscience Publication, New York. 